\title{
Effectiveness of a treatment algorithm for hemodialysis-associated pruritus in terms of changes in medications
}

Naoko Takahashi ${ }^{1 *}$, Taku Yoshizawa ${ }^{1}$, Junko Kumagai ${ }^{1}$, Hideki Kawanishi ${ }^{2}$, Shinichiro Tsuchiya $^{2}$, Misaki Moriishi ${ }^{3}$ and Takao Masaki $^{4}$

\begin{abstract}
Background: Hemodialysis-associated pruritus (HAP) is a serious complication that occurs in $60-80 \%$ of hemodialysis patients, which not only decreases quality of life but also worsens prognosis. We have developed a treatment algorithm to take a comprehensive cause-specific approach to HAP and used it at our facility since June 2009. In this treatment algorithm, moisturizers and topical steroids are used depending on skin condition and severity of pruritus; administration of nalfurafine hydrochloride is considered in treatment-resistant cases. If pruritus improves, we attempt to taper topical steroids by switching to lower potency or by dose reduction or discontinuation. Here, we examined the effectiveness of the treatment algorithm over 9 years in terms of changes in medications.
\end{abstract}

Methods: Subjects were hemodialysis patients who received treatment for HAP at our facility: 89 in May 2009 before introduction of the algorithm, and 131 in April 2013, 164 in October 2014, 190 in October 2015, 181 in October 2016, 215 in October 2017, and 224 patients in October 2018 after its introduction. A questionnaire survey was conducted on the presence of pruritus, severity (using a visual analogue scale [VAS] and Shiratori severity scores), frequency, and insomnia due to pruritus. Changes in medications were investigated using medical records and compared.

Results: The proportion of patients with pruritus decreased significantly from 96.6\% in 2009 to $66.8 \%$ in 2018 ( $p<$ 0.001). Median VAS score significantly decreased from $53.0 \mathrm{~mm}$ in 2009 to $24.5 \mathrm{~mm}$ in 2018 ( $p<0.001)$, and the proportion of patients with insomnia due to pruritus also significantly decreased from $25.8 \%$ in 2009 to $2.2 \%$ in $2018(p<0.001)$. The proportion of patients who used moisturizers significantly increased from 34.8 to $89.7 \%$ ( $p<$ 0.001). The proportion of patients receiving topical steroids decreased from 47.2 to $35.7 \%$, but the difference was not significant $(p=0.085)$.

(Continued on next page)

* Correspondence: n-takahashi@tsuchiya-hp.jp

${ }^{1}$ Akane-Foundation Omachi Tsuchiya Clinic, 2-8-35 Omachi Higashi, Asa

Minami-ku, Hiroshima 731-0124, Japan

Full list of author information is available at the end of the article

C C The Author(s). 2021 Open Access This article is licensed under a Creative Commons Attribution 4.0 International License, which permits use, sharing, adaptation, distribution and reproduction in any medium or format, as long as you give appropriate credit to the original author(s) and the source, provide a link to the Creative Commons licence, and indicate if changes were made. The images or other third party material in this article are included in the article's Creative Commons licence, unless indicated otherwise in a credit line to the material. If material is not included in the article's Creative Commons licence and your intended use is not permitted by statutory regulation or exceeds the permitted use, you will need to obtain permission directly from the copyright holder. To view a copy of this licence, visit http://creativecommons.org/licenses/by/4.0/ The Creative Commons Public Domain Dedication waiver (http://creativecommons.org/publicdomain/zero/1.0/) applies to the data made available in this article, unless otherwise stated in a credit line to the data. 
(Continued from previous page)

Conclusions: The treatment algorithm was shown to be useful for improving HAP, but future challenges were identified, including promoting use of lower potency topical steroids or discontinuation. Further prospective studies are required to confirm the role of each treatment intervention in a comprehensive cause-specific approach to HAP.

Keywords: Hemodialysis-associated pruritus, Quality of life, Visual analogue scale, Shiratori severity score, Treatment algorithm, Moisturizer, Topical steroid, Oral antihistamine

\section{Background}

Hemodialysis-associated pruritus (HAP) is a serious complication that occurs in $60-80 \%$ of hemodialysis patients, which not only decreases quality of life by causing sleep disorders and depressive mood but also worsens prognosis [1-7]. Phase 5 of the Dialysis Outcomes and Practice Patterns Study (DOPPS, 2012-2015), an international multicenter prospective observational study on the prognosis and medical care of hemodialysis patients, revealed that the incidence of pruritus in Japan was 73\%, which was about the same as in previous reports. However, compared with other countries participating in DOPPS, mild pruritus tended to be more common (38\% of hemodialysis patients) and moderate or more severe pruritus tended to be less common (35\%) [8]. These results were largely due to expanded treatment options and improved treatment standards for HAP in Japan, such as the increasing proportion of ultrapure dialysate facilities as a result of a proposal for promoting dialysate purification (2008), the launch of nalfurafine hydrochloride with the indication for treatment-resistant pruritus in hemodialysis patients (2009), the approval of insurance coverage for online hemodiafiltration (OHDF) (2012), and the improved blood purification performance of dialyzers and hemodiafilters.

The causes of HAP are roughly divided into the following three categories: (1) abnormalities caused by renal failure/dialysis, (2) skin abnormalities mainly involving dry skin, and (3) abnormalities in itch control associated with endogenous opioids in the central nervous system. Because these factors act in combination and pruritus is often resistant to treatment, comprehensive cause-specific treatment is required [9-11].

Accordingly, we have developed and introduced a treatment algorithm that has been used in our facility since June 2009 to take a comprehensive cause-specific approach to HAP (Fig. 1) [12]. In this treatment algorithm, moisturizers and topical steroids are used depending on skin condition and severity of pruritus, and administration of nalfurafine hydrochloride is considered

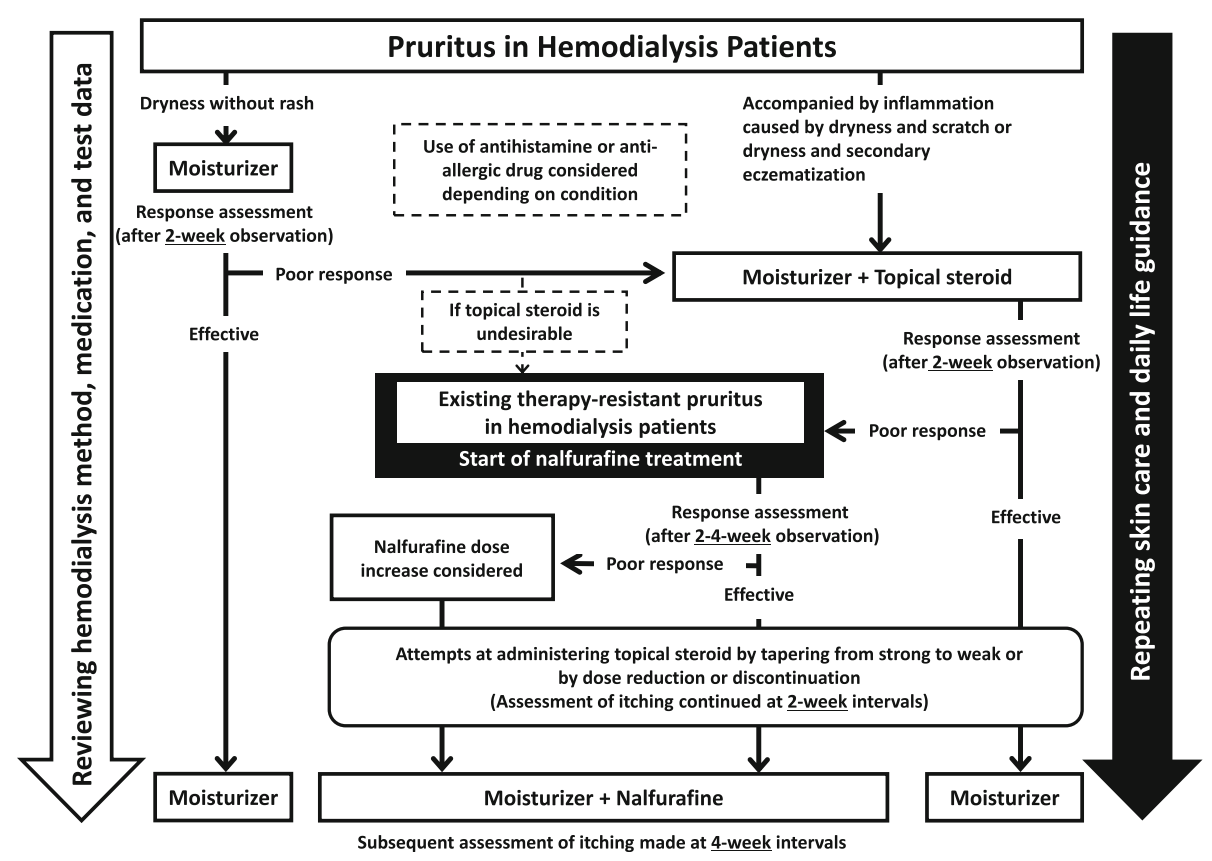

Fig. 1 Treatment algorithm for hemodialysis-associated pruritus 
in treatment-resistant cases. If pruritus improves, we attempt to taper topical steroids by switching to lower potency or by dose reduction or discontinuation. At the same time, we review the dialysis method, medications, and test data and regularly provide guidance on skincare and lifestyle improvements.

In this study, we examined the effectiveness of our treatment algorithm in terms of changes in medications over the 9 years following introduction of the algorithm at our clinic in June 2009.

\section{Methods}

\section{Patients}

Subjects were patients on maintenance hemodialysis who received treatment for HAP at our facility: 89 in May 2009 before the introduction of the treatment algorithm, and 131 in April 2013, 164 in October 2014, 190 in October 2015, 181 in October 2016, 215 in October 2017, and 224 in October 2018 after its introduction. We conducted a questionnaire survey in spring and autumn, when temperature and humidity are considered to have little effect on pruritus. As shown in Table 1, average temperature and humidity are not markedly different between Tokyo and Hiroshima [13]; in other words, there is nothing special about the climate in Hiroshima. A study conducted in Spain showed no seasonal effect in groups with and without pruritus [14]. However, in Japan, it has been reported that pruritus worsens in winter due to dryness, which was confirmed by questionnaire surveys of patients on hemodialysis and those with chronic liver disease $[15,16]$. Pruritus also worsens in the summer because people perspire more due to heat and have more skin damage due to ultraviolet rays. Accordingly, we did not conduct the survey during winter or summer.

A questionnaire survey was conducted on the presence of pruritus, its severity and frequency, and insomnia due to pruritus. Furthermore, changes in medications were investigated using medical records and compared. Table 2 shows the baseline characteristics of the subjects.

\section{Severity of pruritus}

Severity of pruritus was evaluated using a visual analogue scale (VAS) [17-20] and Shiratori severity scores [21]. VAS scores were determined by asking patients about the severity of pruritus when they recently experienced the worst itch. They recorded their answer by drawing a vertical line on a straight horizontal line with the left end set as "no itch" $(0 \mathrm{~mm})$ and the right end set as "worst possible itch" (100 $\mathrm{mm})$, and responses were measured as the distance (millimeters) from the left end to the vertical line.

The intensity of pruritus according to Shiratori severity scores was determined by evaluating daytime and nighttime pruritus separately. Daytime pruritus was evaluated on a 5-point scale: $0=$ "No itching at all" (no symptoms), 1 = "Tolerable without scratching" (very mild), 2 = "Subsides after light scratching" (mild), 3 = "Subsides after considerable scratching" (moderate), and $4=$ "Does not subside, prompting repeated scratching" (severe). Nighttime pruritus was evaluated on the following 5-point scale: $0=$ "No itching at all" (no symptoms), 1 = "Slight itching at bedtime, but not to the extent that I consciously scratch; I sleep well" (very mild), 3 = "I wake up due to itching; I can fall asleep after scratching once but unconsciously scratch while asleep" (moderate), and 4 = "I can hardly sleep due to itching; I constantly scratch, but it makes me itchier" (severe).

The frequency of itching was evaluated on the following 6-point scale: "never," "not every day," "once a day," "a few times a day," "4 or more times a day," and "always."

Insomnia due to pruritus was evaluated using a "yes" or "no" question.

We investigated changes over time in the number of patients using each of the following medications: moisturizers, topical steroids, topical antihistamines, other topical agents, anti-allergic injections, oral antihistamines, and nalfurafine hydrochloride. For topical steroids, we also investigated changes over time in the number of patients using them by potency.

The moisturizers used included highly purified white petrolatum (oleaginous base), heparinoid preparations, and urea-containing preparations. Bases used for heparinoid preparations were water-in-oil emulsion (cream), oil-in-water emulsion (cream or lotion), or undiluted liquid formulations (foam). Bases used for urea-

Table 1 Average temperature and humidity in Hiroshima City and Tokyo

\begin{tabular}{llllllll}
\hline Year/month of survey & $\mathbf{2 0 0 9 / 5}$ & $\mathbf{2 0 1 3 / 4}$ & $\mathbf{2 0 1 4 / 1 0}$ & $\mathbf{2 0 1 5 / 1 0}$ & $\mathbf{2 0 1 6 / 1 0}$ & $\mathbf{2 0 1 7 / 1 0}$ & $\mathbf{2 0 1 8 / 1 0}$ \\
\hline Hiroshima: average temperature $\left({ }^{\circ} \mathrm{C}\right)$ & 19.8 & 13.5 & 18.7 & 18.0 & 20.2 & 18.4 & 18.5 \\
Hiroshima: average humidity $(\%)$ & 55 & 61 & 67 & 58 & 66 & 70 & 61 \\
Tokyo: average temperature $\left({ }^{\circ} \mathrm{C}\right)$ & 20.1 & 15.2 & 19.1 & 18.4 & 18.7 & 16.8 & 19.1 \\
Tokyo: average humidity $(\%)$ & 64 & 55 & 67 & 66 & 72 & 82 & 74 \\
\hline
\end{tabular}

The average annual temperature was $17^{\circ} \mathrm{C}$ and the average annual humidity was $61 \%$ in Hiroshima City in 2020 (compiled by the authors based on data from the Japanese Meteorological Agency [13]) 
Table 2 Patient background

\begin{tabular}{|c|c|c|c|c|c|c|c|c|}
\hline & 2009 & 2013 & 2014 & 2015 & 2016 & 2017 & 2018 & $P$ value \\
\hline Number of patients & 89 & 131 & 164 & 190 & 181 & 215 & 224 & \\
\hline Men/women & $\begin{array}{l}62(69.7) / 27 \\
(30.3)\end{array}$ & $\begin{array}{l}89(67.9) / 42 \\
(32.1)\end{array}$ & $\begin{array}{l}102(62.2) / 62 \\
(37.8)\end{array}$ & $\begin{array}{l}125(65.8) / 65 \\
(34.2)\end{array}$ & $\begin{array}{l}113(62.4) / 68 \\
(37.6)\end{array}$ & $\begin{array}{l}136(63.3) / 79 \\
(36.7)\end{array}$ & $\begin{array}{l}140(62.5) / 84 \\
(37.5)\end{array}$ & $0.801^{*}$ \\
\hline Median age (IQR), years & $\begin{array}{l}68(61.0- \\
76.5)\end{array}$ & $\begin{array}{l}71(64.0- \\
77.0)\end{array}$ & $71(65.0-78.0)$ & $72(65.0-78.0)$ & $72(65.0-79.0)$ & $71(66.0-78.0)$ & $72(66.0-79.0)$ & $0.127^{* *}$ \\
\hline $\begin{array}{l}\text { Median duration of HD (IQR), } \\
\text { months }\end{array}$ & $\begin{array}{l}63(29.0- \\
98.0)\end{array}$ & $\begin{array}{l}75(27.0- \\
137.0)\end{array}$ & $\begin{array}{l}68.5(32.0- \\
136.5)\end{array}$ & $\begin{array}{l}60(31.5- \\
119.3)\end{array}$ & $\begin{array}{l}65(34.0- \\
142.0)\end{array}$ & $\begin{array}{l}71(32.0- \\
136.0)\end{array}$ & $\begin{array}{l}77(33.0- \\
151.0)\end{array}$ & $0.402^{* *}$ \\
\hline \multicolumn{9}{|l|}{ Primary cause of CKD } \\
\hline Diabetes mellitus & $41(46.1)$ & 65 (49.6) & $78(47.6)$ & $94(49.5)$ & $84(46.4)$ & $98(45.6)$ & $106(47.3)$ & \\
\hline Chronic glomerulonephritis & $24(27.0)$ & $35(26.7)$ & $41(25.0)$ & $41(21.6)$ & $41(22.7)$ & $50(23.3)$ & $42(18.8)$ & \\
\hline Nephrosclerosis & $6(6.7)$ & $8(6.1)$ & $20(12.2)$ & $20(10.5)$ & $22(12.2)$ & $26(12.1)$ & $34(15.2)$ & $0.787^{*}$ \\
\hline Other & $6(6.7)$ & $8(6.1)$ & $9(5.5)$ & $15(7.9)$ & $17(9.4)$ & $22(10.2)$ & $21(9.4)$ & \\
\hline Unknown & $12(13.5)$ & $15(11.5)$ & $16(9.8)$ & $20(10.5)$ & $17(9.4)$ & $19(8.8)$ & $21(9.4)$ & \\
\hline \multicolumn{9}{|l|}{ Dialysis method } \\
\hline$H D$ & $89(100)$ & $121(93.8)$ & $142(86.6)$ & $137(72.1)$ & $103(56.9)$ & $92(42.8)$ & $78(34.8)$ & \multirow{3}{*}{$\begin{array}{l}< \\
0.001^{*}\end{array}$} \\
\hline OHDF & $0(0)$ & $8(6.2)$ & $18(11.0)$ & $47(24.7)$ & $75(41.4)$ & $113(52.6)$ & $129(57.6)$ & \\
\hline I-HDF & $0(0)$ & $0(0)$ & $4(2.4)$ & $6(3.2)$ & $3(1.7)$ & $10(4.7)$ & $17(7.6)$ & \\
\hline PMMA membrane dialyzer & $4(4.5)$ & $17(13.0)$ & $42(25.6)$ & $45(23.7)$ & $36(19.9)$ & $45(20.9)$ & $33(14.7)$ & $\begin{array}{l}< \\
0.001^{*}\end{array}$ \\
\hline Median spKt/Nurea [IQR] & $1.6[1.4,1.8]$ & $1.6[1.4,1.8]$ & $1.7[1.4,1.9]$ & $1.6[1.5,1.8]$ & $1.7[1.5,1.8]$ & $1.7[1.5,1.8]$ & $1.7[1.5,1.9]$ & $\begin{array}{l}< \\
0.01^{* *}\end{array}$ \\
\hline
\end{tabular}

Data are presented as number (\%), unless stated otherwise

$P$ values were calculated using Fisher's exact test $\left({ }^{*}\right)$ or Kruskal-Wallis test $\left({ }^{* *}\right)$

$C K D$ chronic kidney disease, $H D$ hemodialysis, $I-H D F$ intermittent infusion hemodiafiltration, IQR interquartile range, $O H D F$ online hemodiafiltration, $P M M A$

polymethylmethacrylate, spKt/Vurea single-pool Kt/Vurea

The median spKt/Vurea values in $2016(p<0.05), 2017(p<0.05)$, and $2018(p<0.01)$ were significantly different from that in 2009

containing preparations were oil-in-water emulsions (creams). These moisturizers were used individually or in combination depending on the level of skin dryness, the site of application, time of day, season, and patient preference.

\section{Statistical analysis}

Fisher's exact test and the Kruskal-Wallis test were used for comparisons among all groups, and the JonckheereTerpstra test was used for trend analysis. All statistical analyses were performed using SPSS version 23.0 for Windows (IBM Japan Ltd., Tokyo, Japan).

\section{Ethical approval}

This study was approved by the Ethics Review Committee at the Tsuchiya General Hospital (approval number, E191216-1) and was conducted according to the principles of the Declaration of Helsinki. Verbal consent was obtained from all enrolled subjects prior to the study. The fact that the subject gave consent was recorded in the medical chart. Written informed consent was waived due to the nature of this observational study and our strict maintenance of patient anonymity.

\section{Results}

\section{Presence of pruritus}

The number of patients who reported having pruritus significantly decreased from 86 (96.6\%) in 2009 before introduction of the treatment algorithm to $122(93.1 \%)$ in $2013,144(87.8 \%)$ in $2014,145(76.3 \%)$ in 2015,140 (77.3\%) in 2016, 153 (71.2\%) in 2017, and 154 (66.8\%) in 2018 after its introduction $(p<0.001$ for trend).

\section{Severity of pruritus}

Median VAS score (IQR) significantly decreased from 53.0 (40.0, 74.0) $\mathrm{mm}$ in 2009 before introduction of the treatment algorithm to $48.0(27.0,67.0) \mathrm{mm}$ in 2013, $38.0(19.0,61.0) \mathrm{mm}$ in 2014, $30.0(5.8,50.0)$ $\mathrm{mm}$ in $2015,21.0(5.0,38.0) \mathrm{mm}$ in 2016, $16.0(0.0$, $32.0) \mathrm{mm}$ in 2017, and $24.5(0.0,50.0) \mathrm{mm}$ in 2018 after its introduction ( $p<0.001$ for trend) (Fig. 2). The median Shiratori severity score (IQR) for daytime pruritus significantly decreased from $2.0(2.0,3.0)$ in 2009 before introduction of the treatment algorithm to $2.0(1.0,2.0)$ in $2013,2.0(1.0,2.0)$ in $2014,1.0$ $(0.0,2.0)$ in $2015,1.0(0.0,2.0)$ in $2016,1.0(0.0,2.0)$ in 2017 , and $1.0(0.0,2.0)$ in 2018 after the introduction $(p<0.01$ for trend). The median Shiratori severity score for nighttime pruritus also significantly 


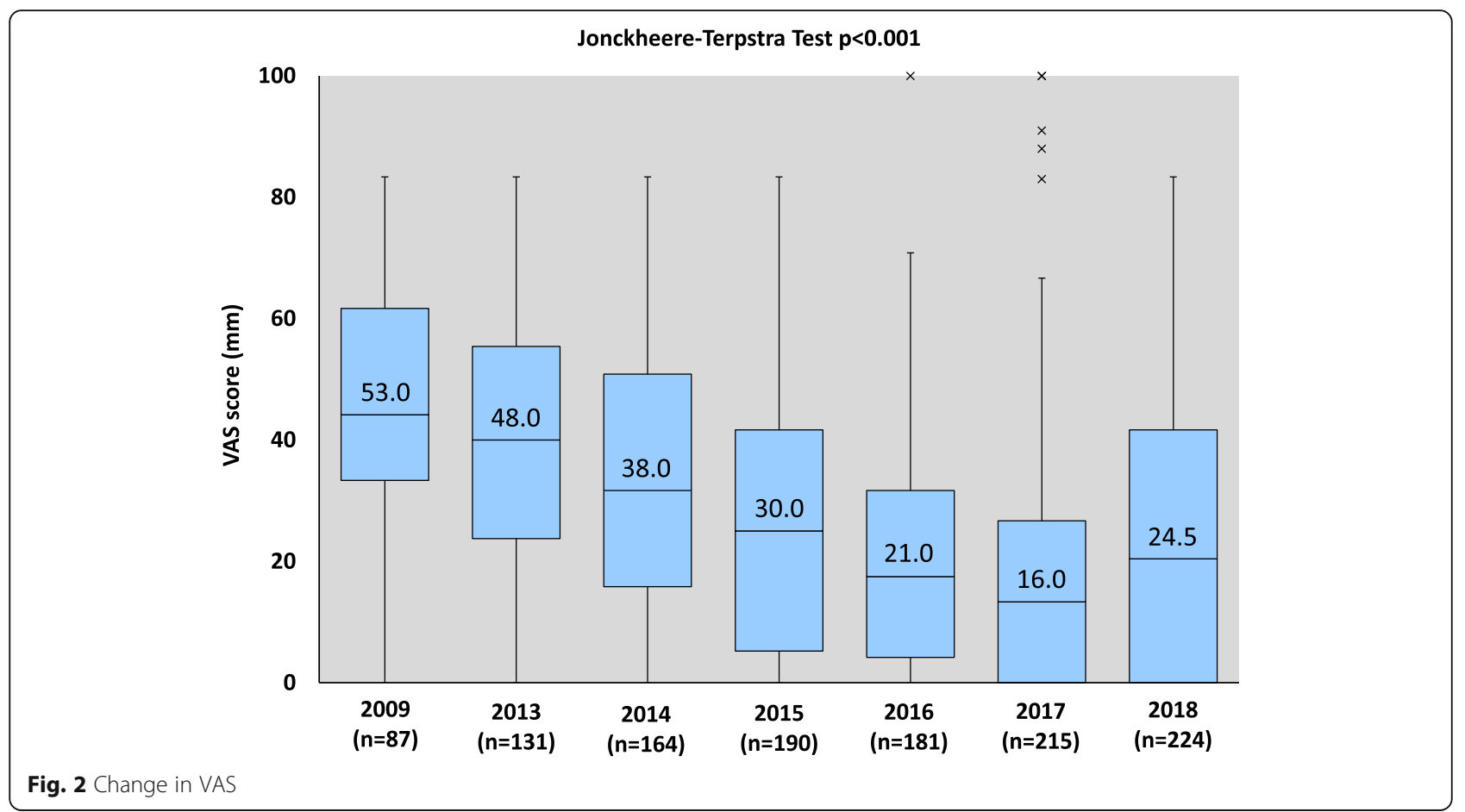

decreased from $2.0(1.0,2.0)$ in 2009 to $2.0(1.0,2.0)$ in $2013,2.0(1.0,2.0)$ in $2014,1.0(0.0,1.3)$ in 2015 , $1.0(0.0,1.0)$ in $2016,1.0(0.0,1.0)$ in 2017, and 0 $(0.0,1.0)$ in 2018 ( $p<0.001$ for trend).

The Shiratori severity score for daytime pruritus before introduction of the treatment algorithm in 2009 was "no symptoms" in 3 patients (3.4\%), "very mild" in $2(2.2 \%)$, "mild" in 40 (44.9\%), "moderate" in 24
(27.0\%), and "severe" in 20 (22.5\%). After its introduction, the number of patients categorized as "very mild" or lower increased, whereas the number of patients categorized as "mild" or more severe decreased. In 2018, the results were "no symptoms" in 74 patients (33.0\%), "very mild" in 80 (35.7\%), "mild" in 62 (27.7\%), "moderate" in 7 (3.1\%), and "severe" in 1 $(0.4 \%)$ ( $p<0.001$ for trend) (Fig. 3).

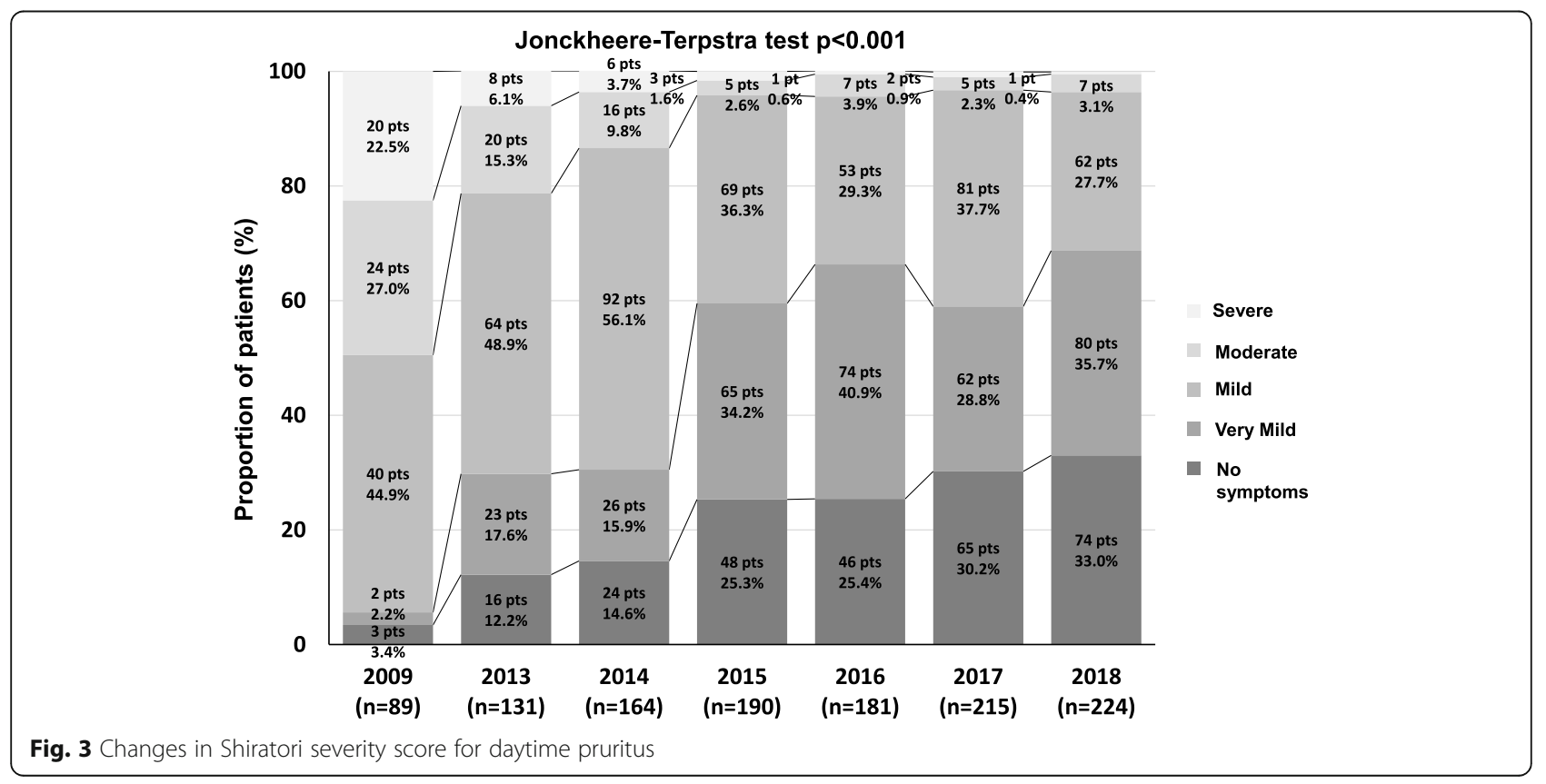


The Shiratori severity score for nighttime before introduction of the treatment algorithm in 2009 were "no symptoms" in 12 patients (13.5\%), "very mild" in 16 (18.0\%), "mild" in 41 (46.1\%), "moderate" in 18 (20.2\%), and "severe" in $2(2.2 \%)$. After its introduction, the number of patients categorized as "very mild" or lower increased, whereas that of patients categorized as "mild" and more severe decreased. In 2018, the results were "no symptoms" in 125 patients (55.8\%), "very mild" in 66 (29.5\%), "mild" in 27 (12.1\%), "moderate" in 4 (1.8\%), and "severe" in $2(0.9 \%)(p<0.001$ for trend) (Fig. 4).

Changes in the severity of pruritus were compared according to whether the primary cause of CKD was diabetic mellitus or not. As shown Table 3, significant reduction in severity was observed regardless of whether patients had diabetes mellitus or not.

\section{Frequency of pruritus}

The frequency of pruritus was not included in the questionnaire survey for 3 years from 2013 to 2015, and therefore, it was compared between the survey results of 2009 before introduction of the treatment algorithm and those of 2016, 2017, and 2018 after its introduction (Fig. 5). In 2009, the frequency was "never" in 3 patients (3.4\%), "not every day" in 21 (23.6\%), "once a day" in 9 (10.1\%), "a few times a day" in 39 (43.8\%), "4 or more times a day" in 9 (10.1\%), and "always" in 8 (9.0\%). After introduction of the treatment algorithm, the number of patients reporting itch "once a day" or less increased, while the number reporting itch "a few times a day" or more decreased. In 2018, "never," "not every day," "once a day," "a few times a day," " 4 or more times a day," and "always" were reported by 70 patients (31.3\%), 60 (26.8\%), 29 (12.9\%), 49 (21.9\%), 11 (4.9\%), and $5(2.2 \%)$, respectively.

\section{Insomnia due to pruritus}

The number of patients who reported having insomnia due to pruritus significantly decreased from 23 patients (25.8\%) in 2009 before introduction of the treatment algorithm to 17 patients (13.0\%) in 2013, $25(15.2 \%)$ in 2014, 11 (5.8\%) in 2015, $13(7.2 \%)$ in 2016, 20 (9.3\%) in 2017 , and $5(2.2 \%)$ in 2018 after its introduction $(p<$ 0.001 for trend).

\section{Changes in medications}

Table 4 shows the changes in medications used. The proportion of patients who used moisturizers was $34.8 \%$ in 2009 before introduction of the treatment algorithm but increased significantly after its introduction to $89.7 \%$ in $2018(p<0.001)$. The proportion of patients who used topical steroids was $47.2 \%$ in 2009 before introduction of the treatment algorithm and $35.7 \%$ in 2018 after its introduction, showing a decreasing tendency but not a significant difference $(p$ $=0.085)$. The proportion of patients who used topical antihistamines and anti-allergic injections decreased significantly $(p<0.005$ and $p<0.001$, respectively). The proportion of patients who used oral antihistamines was $40.4 \%$ in 2009 before introduction of the treatment algorithm but decreased significantly to

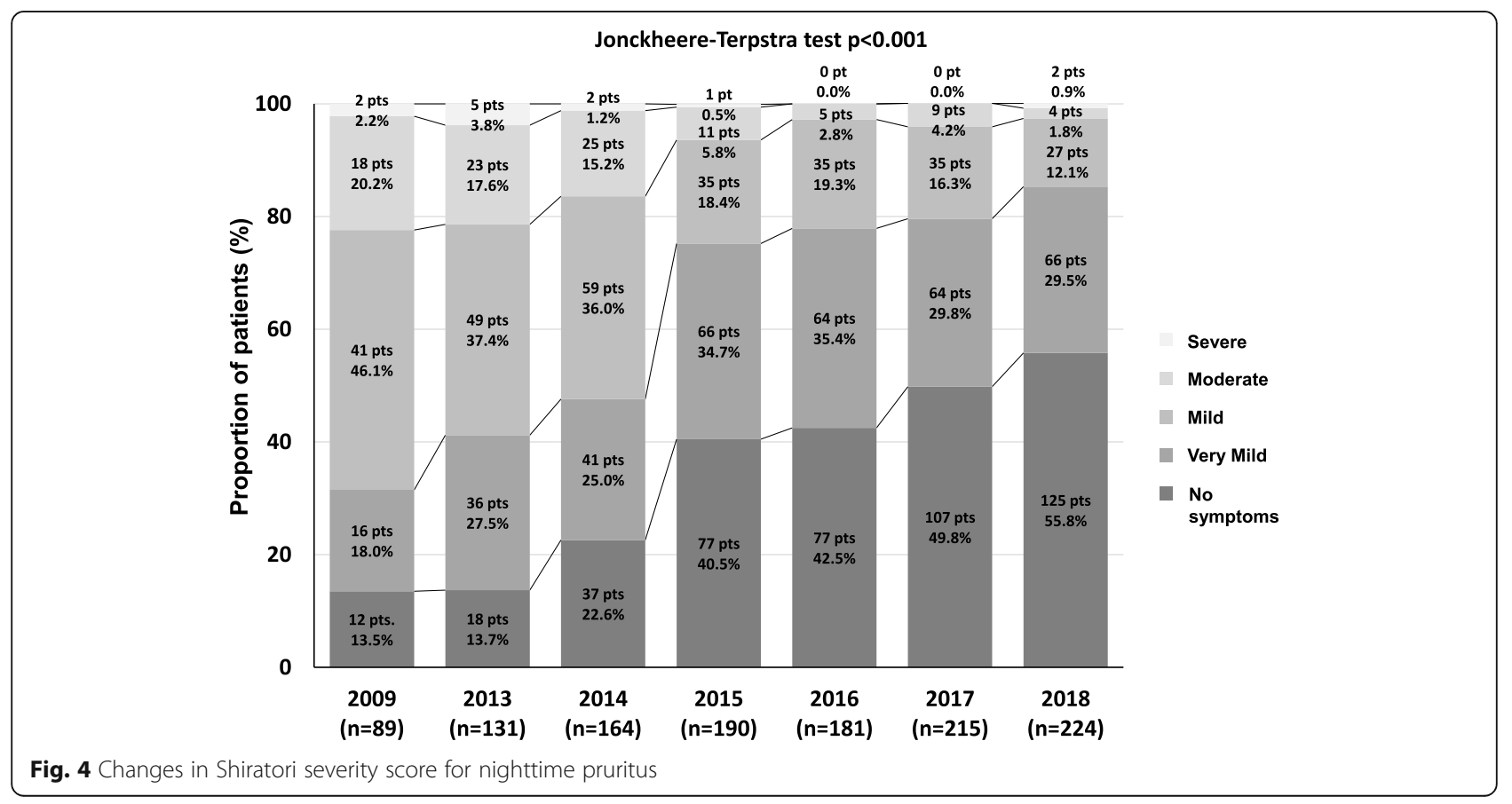


Table 3 Changes in the severity of pruritus between patients with and those without diabetes mellitus

\begin{tabular}{|c|c|c|c|c|c|c|c|c|}
\hline Patient group & 2009 & 2013 & 2014 & 2015 & 2016 & 2017 & 2018 & $P$ value* \\
\hline $\mathrm{DM}$ & $n=41$ & $n=65$ & $n=78$ & $n=94$ & $n=84$ & $n=98$ & $n=106$ & \\
\hline $\begin{array}{l}\text { Median Shiratori severity score for } \\
\text { daytime pruritus [IQR] }\end{array}$ & $2[2,3]$ & $2[1,2]$ & $2[1,2]$ & $1[1,2]$ & $1[1,2]$ & $1[0,2]$ & $1[0,2]$ & $<0.001$ \\
\hline $\begin{array}{l}\text { Median Shiratori severity score for } \\
\text { nighttime pruritus [IQR] }\end{array}$ & $2[1,2]$ & $2[1,2]$ & $2[0.3,2]$ & $1[0,2]$ & $1[0,1]$ & $1[0,1]$ & $1[0,1]$ & $<0.001$ \\
\hline Median VAS score [IQR] (mm) & $51[40,66.5]$ & $48[30,68]$ & $34[19.3,56.3]$ & $35[11.5,60]$ & $22[10.8,42]$ & $21[0.3,37.3]$ & $23.5[0,50]$ & $<0.001$ \\
\hline Non-DM & $n=48$ & $n=66$ & $n=86$ & $n=96$ & $n=97$ & $n=117$ & $n=118$ & \\
\hline $\begin{array}{l}\text { Median Shiratori severity score for } \\
\text { daytime pruritus [IQR] }\end{array}$ & $3[1.3,3]$ & $2[1,2]$ & $2[1,2]$ & $1[0,2]$ & $1[0,2]$ & $1[0,2]$ & $1[0,2]$ & $<0.001$ \\
\hline $\begin{array}{l}\text { Median Shiratori severity score for } \\
\text { nighttime pruritus [IQR] }\end{array}$ & $2[2,3]$ & $2[1,2]$ & $2[1,2]$ & $1[0,1]$ & $1[0,1]$ & $0[0,1]$ & $0[0,1]$ & $<0.001$ \\
\hline Median VAS score [IQR] (mm) & $54[40.8,74.5]$ & $46.5[27.8,60]$ & $40[20,61]$ & $25[2,49]$ & $20[0,33]$ & $15[0,30]$ & $25.5[0,50.8]$ & $<0.001$ \\
\hline
\end{tabular}

*P values were calculated using the Kruskal-Wallis test

$10.7 \%$ in 2018 after its introduction $(p<0.001)$. The proportion of patients who used nalfurafine hydrochloride was $23.7 \%$ in $2013,22.6 \%$ in $2014,21.1 \%$ in 2015 , and $21.5 \%$ in 2016 , but decreased to $13.5 \%$ in 2017 and $14.3 \%$ in 2018, showing a decreasing trend.

The proportion of patients using topical steroids by potency was "strongest" in 9.5\%, "very strong" in $71.4 \%$, "strong" in 16.7\%, and "medium" in $2.4 \%$ in 2009 before introduction of the treatment algorithm. However, after its introduction, the proportion of patients using "strongest" topical steroids decreased, while the proportion of patients using "strong" or "medium" topical steroids showed an increasing tendency. In 2018, the proportions for "strongest" and "very strong" were 6.3\% and 22.5\%, respectively, while the proportions for "strong" and "medium" were $61.3 \%$ and $10 \%$, respectively $(p<0.001)$ (Fig. 6).

\section{Discussion}

We reviewed our treatment policy for HAP and developed and introduced a new treatment algorithm in June 2009 [12]. According to this treatment algorithm, moisturizers and topical steroids are used depending on skin condition and severity of pruritus, and administration of nalfurafine hydrochloride is considered in treatmentresistant cases. At the same time, we review the dialysis method, medication, and test data and regularly provide guidance on skincare and lifestyle improvements. Accumulation of uremic substances due to insufficient dialysis is a major cause of pruritus. To address this,

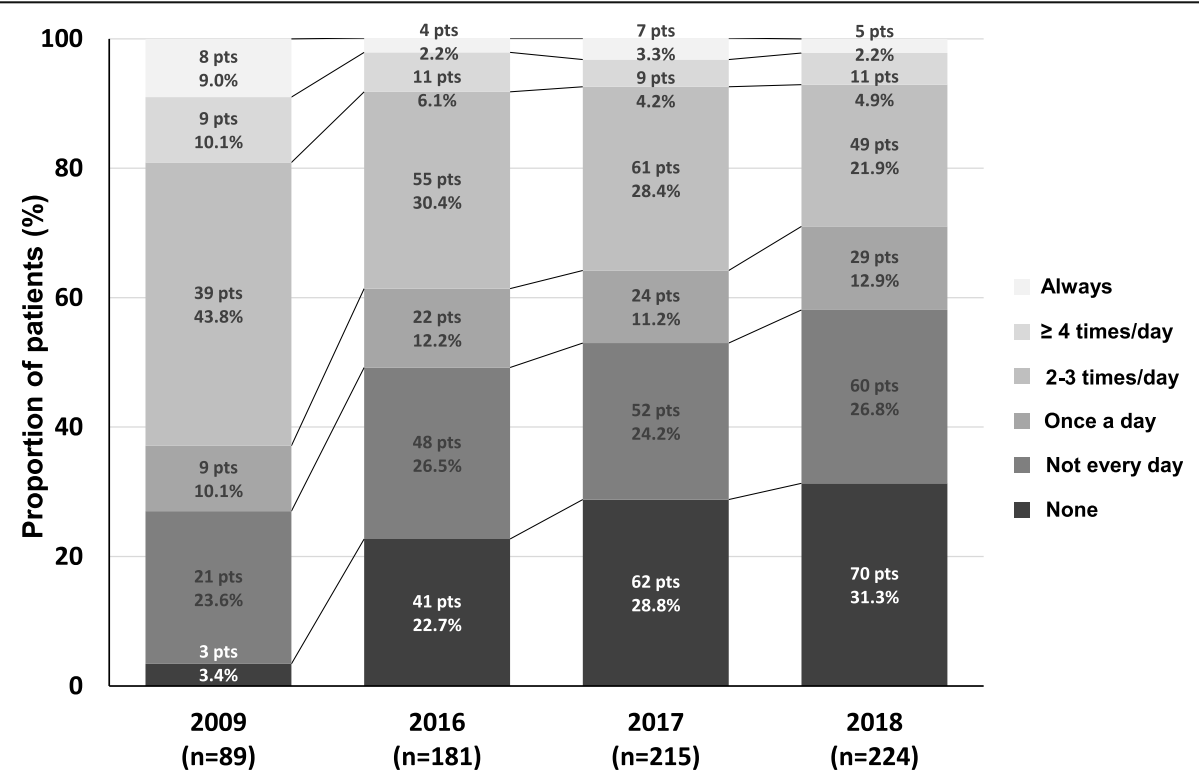

Fig. 5 Changes in the frequency of pruritus 
Table 4 Changes in the number of patients by drug

\begin{tabular}{|c|c|c|c|c|c|c|c|c|}
\hline & $\begin{array}{l}2009 \\
(n=89)\end{array}$ & $\begin{array}{l}2013 \\
(n=131)\end{array}$ & $\begin{array}{l}2014 \\
(n=164)\end{array}$ & $\begin{array}{l}2015 \\
(n=190)\end{array}$ & $\begin{array}{l}2016 \\
(n=181)\end{array}$ & $\begin{array}{l}2017 \\
(n=215)\end{array}$ & $\begin{array}{l}2018 \\
(n=224)\end{array}$ & $P$ value* \\
\hline Moisturizers & $31(34.8)$ & $85(64.9)$ & $134(81.7)$ & $151(79.5)$ & $142(78.5)$ & $184(85.6)$ & $201(89.7)$ & $<0.001$ \\
\hline Topical steroids & $42(47.2)$ & $68(51.9)$ & $70(42.7)$ & $78(41.1)$ & $83(45.9)$ & $87(40.5)$ & $80(35.7)$ & 0.085 \\
\hline Topical antihistamines & $4(4.5)$ & $4(3.1)$ & $1(0.6)$ & $0(0.0)$ & $1(0.6)$ & $0(0.0)$ & $1(0.4)$ & $<0.005$ \\
\hline Other topical drugs & $17(19.1)$ & $13(9.9)$ & $8(4.9)$ & $19(10.0)$ & $35(19.3)$ & $34(15.8)$ & $28(12.5)$ & $<0.005$ \\
\hline Anti-allergy injections & $29(32.6)$ & $10(7.6)$ & $4(2.4)$ & $1(0.5)$ & $2(1.1)$ & $2(0.9)$ & $3(1.3)$ & $<0.001$ \\
\hline Oral antihistamines & $36(40.4)$ & $35(26.7)$ & 19 (11.6) & $22(11.6)$ & $13(7.2)$ & $24(11.2)$ & $24(10.7)$ & $<0.001$ \\
\hline Nalfurafine hydrochloride & $0(0.0)$ & $31(23.7)$ & $37(22.6)$ & $40(21.1)$ & $39(21.5)$ & 29 (13.5) & $32(14.3)$ & $<0.001$ \\
\hline
\end{tabular}

Data are presented as number (\%)

${ }^{*} P$ values were calculated using Fisher's exact test

sufficient dialysis should be performed to efficiently remove uremic substances that cause pruritus using a blood purifier with good biocompatibility. Specifically, hemodialysis using a polymethylmethacrylate membrane dialyzer with good biocompatibility and high protein adsorption capacity, which is superior for removing high molecular weight substances larger than albumin [2227] and OHDF with good biocompatibility and effectiveness for removing protein-bound uremic toxins and low molecular weight proteins should be proactively performed [28-31].

We have previously reported the effectiveness of this treatment algorithm [12, 32], and in the present report, we further verified the long-term utility of the treatment algorithm in terms of the changes in medications over 9 years up to 2018.

Our result indicates that the number of patients with pruritus was significantly decreased by treatment based on the algorithm. For severity of pruritus, significant reductions in VAS scores were seen. In addition, the severity of both daytime and nighttime pruritus according to Shiratori severity scores was significantly improved, as shown by the increase in patients with "very mild" pruritus or "no symptoms" and the decrease in patients with "mild" or more severe pruritus for both daytime and nighttime pruritus. The frequency of pruritus was also reduced, and the number of patients with insomnia due to pruritus significantly decreased.

Increases in VAS score were confirmed in 2018, but disease aggravation was not confirmed based on the evaluation using Shiratori severity score, which is considered to reflect the actual severity of pruritus. The present study showed significant alleviation of pruritus symptoms compared with 2009 based on the evaluation using the VAS score and Shiratori severity score, indicating that pruritus symptoms were managed in a

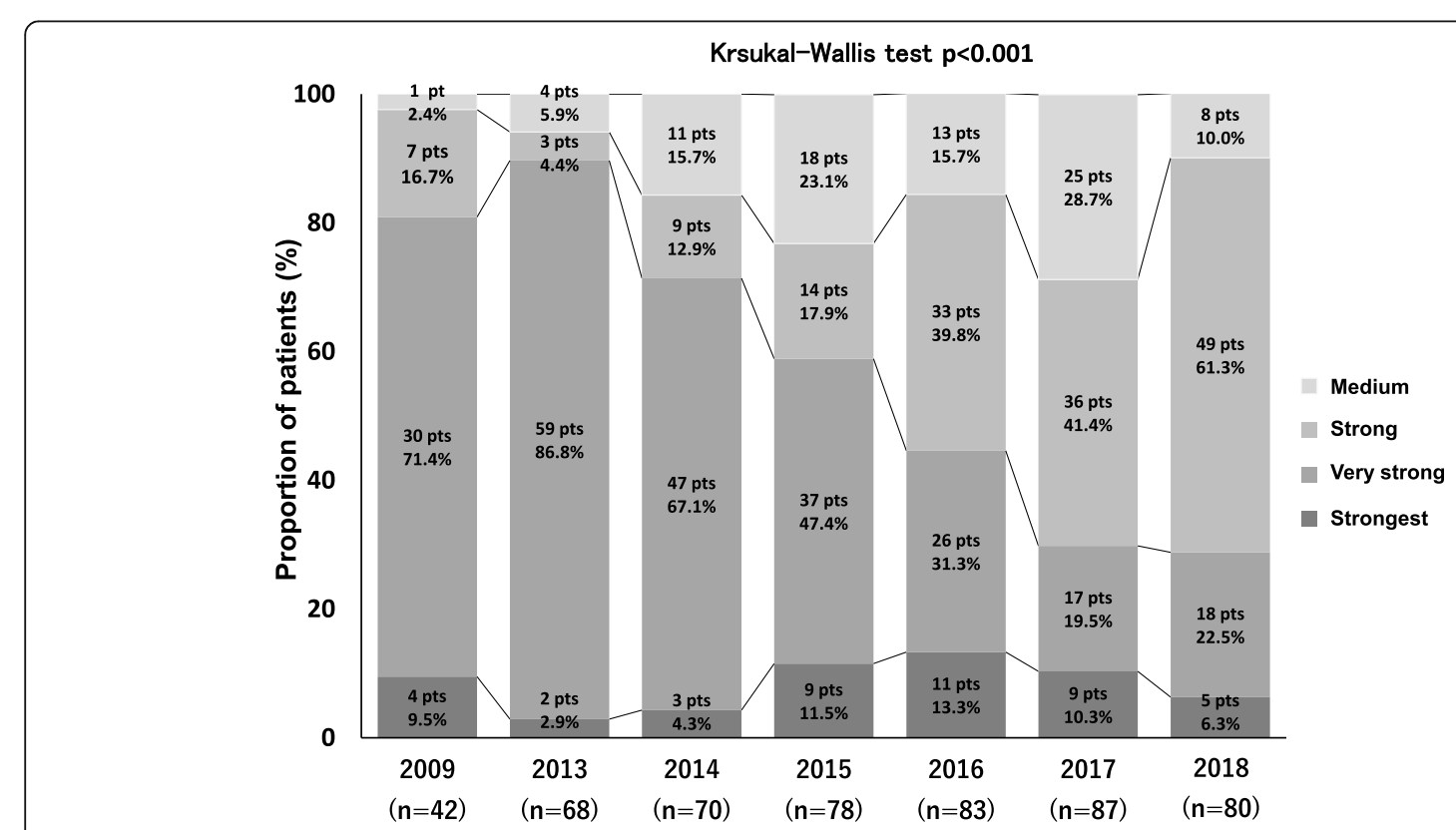

Fig. 6 Changes in the proportion of patients using topical steroid by potency 
considerable proportion of the patients. When symptoms develop under such circumstances, sensitivity to itch is likely to increase, which might have contributed to the greater-than-expected increase in VAS score in 2018.

A multidisciplinary medical team consisting of physicians, nurses, pharmacists, and clinical engineers provided care in accordance with "Repeating skin care and daily life guidance," and this might be an important factor for improvement in pruritus symptoms during the day and at night, based on the evaluation using Shiratori severity score. Continued use of appropriate topical medications (e.g., moisturizers) and oral medications for pruritus is important for managing HAP. However, many hemodialysis patients in Japan are elderly, and they often cannot administer appropriate topical medications by themselves, and they take many other oral medications, which can result in the poor medication adherence. To address this, we have been making a considerable effort to support such patients through a multidisciplinary team approach. Nurses not only examine the patient's skin conditions and administer topical medications at the facility, but also explain the importance of these medications to the patient's family and provide instructions on how to apply them at home. Pharmacists continue to manage prescriptions and promote the use of single-dose packages, thereby improving medication adherence. Clinical engineers work to determine effective dialysis methods (e.g., OHDF) for reducing and managing pruritus. We believe that these measures collectively relieved both daytime and nighttime pruritus symptoms.

As for the changes in medications, the use of moisturizers increased significantly and they were used by $89.7 \%$ of patients in 2018. In dialysis patients, water supply to the skin is reduced due to water removal by dialysis and restricted water intake, resulting in decreased water content in the stratum corneum, and the amount of sebum and sweat secretion is reduced due to atrophy of the sebaceous glands and sweat glands, resulting in insufficient sebum film formation. Therefore, the frequency of dry skin is high at $90.9 \%$ in dialysis patients [33], and some studies have found the frequency of moderate and severe dryness to be as high as 59.3 to $93.1 \%$ [34]. In dry skin, there is impaired barrier function of the skin (the function preventing water evaporation from the skin and protecting against external stimuli), and the free nerve endings of the $\mathrm{C}$-fibers, which are itch nerves that normally converge at the border of the epidermis and dermis, extend to near the skin surface just below the stratum corneum in the epidermis [35]. This causes hypersensitivity of the skin and a lower itch threshold, and itch receptors present at free nerve endings of Cfibers are directly stimulated by slight external stimuli, such as rubbing by clothes. The resulting nerve excitation is transmitted centrally from the spinal cord to the thalamus to the sensory area of the cerebral cortex and recognized as itch [36]. Dry skin has been reported to be a factor in severe HAP [37]. Moisturizers improve the barrier function of the skin, restore elongated C-fibers to their original state, decrease skin hypersensitivity, elevate the itch threshold, and improve pruritus symptoms [38], indicating that skincare with a moisturizer is a necessary first step for patients with dry skin but no rash.

In this treatment algorithm, topical steroids are used in cases with scratch-induced inflammation and secondary eczema because of their strong and rapid antiinflammatory action and suppression of allergic reactions. Once pruritus improves, we attempt to taper topical steroids by switching to a lower potency, dose reduction, and discontinuation. The number of patients using topical steroids tended to decrease after the introduction of the treatment algorithm, but the difference was not significant. However, of the topical steroids that were used, there was a decrease in those that were "very strong" and an increase in those that were "strong" and "medium," and there was a significant difference according to potency.

It has been reported that some patients who used strong topical steroids for atopic dermatitis showed suppressed adrenal function, but in patients who used weak topical steroids no adrenal function suppression or growth disorder were observed [39], indicating that topical steroids, when used appropriately, are safe and do not cause systemic side effects. Topical side effects include skin atrophy, telangiectasia, as well as bacterial, fungal, and viral skin infections. However, as mentioned in the Japanese guidelines for the treatment of atopic dermatitis, the side effects of long-term topical steroids are not severe and all but skin atrophy are transient, indicating that they can be reduced by using weaker steroids or reducing the dosing frequency. Indeed, we have never observed severe side effects due to use of topical steroids since the introducing the treatment algorithm in 2009. Nevertheless, as mentioned above, there is a risk of side effects, and the strength of steroids should be carefully considered according to the intensity of itching, the site of application, and the skin condition. According to our treatment algorithm, topical steroids should be used only for dryness- or scratch-induced inflammation, and secondary eczema. The possibility of reducing the dose and using weaker steroids should be actively investigated. If no therapeutic effect is observed, the medication should be discontinued and switched to moisturizers and nalfurafine hydrochloride at an early stage. To avoid side effects caused by a long-term use of topical steroids, a remaining challenge is to further promote switching to less potent topical steroids and discontinuation of topical steroids. 
Also, the proportions of patients using oral antihistamines, topical antihistamines, and anti-allergic injections all significantly decreased. Among these, antihistamines have been frequently used as therapeutic agents for HAP and have been reported to be effective. However, their use has not been sufficiently verified and, if taken orally, may cause dangerous side effects associated with oversedation. For this reason, antihistamines are not recommended as a first-line drug for chronic kidney disease-associated pruritus [6]. At our facility, we may use antihistamines depending on the patient's condition, but we limit their use to third- and fourth-generation non-sedating drugs with no description of warnings for operating hazardous machinery, such as driving a motor vehicle, on the package insert (fexofenadine, loratadine, desloratadine, and bilastine) and we prescribe a reduced dose or discontinue use once pruritus has improved. The results seem to reflect our policy.

According to the treatment algorithm, nalfurafine hydrochloride is used in cases where pruritus is resistant to various treatments and endogenous opioids are suspected to be involved in the cause. In other words, administration of nalfurafine hydrochloride is indicated for patients in whom combination use of moisturizers and topical steroids is ineffective despite sufficient removal of uremic substances and those in whom moisturizers are ineffective but topical steroids cannot be used and the involvement of endogenous opioids is suspected. It has been reported that among endogenous opioids, the $\mu$-opioid system induces itch, while the $\mathrm{k}$-opioid system suppresses it; in dialysis patients with more severe pruritus, the serum concentration of $\beta$-endorphin, which is an endogenous $\mu$-opioid peptide, is higher, and also, the ratio of the concentration of $\beta$-endorphin to that of dynorphin $\mathrm{A}$, which is an endogenous $\mathrm{k}$-opioid peptide that suppresses inch, is higher [40].

Nalfurafine hydrochloride activates the k-opioid system by binding to $\mathrm{k}$-opioid receptors in the central nervous system, such as the posterior horn of the spinal cord and the thalamus, thereby relatively inhibiting the $\mu$-opioid system and reducing itch $[41,42]$. Interestingly, $\mu$-opioid receptors and their endogenous ligand $\beta$ endorphin and $\mathrm{k}$-opioid receptors and their ligands dynorphins have been found also in the epidermis, dermis, and afferent C-fibers [43, 44]. Furthermore, it has been recently reported that there was no significant difference in $\mu$-opioid receptor expression in the skin between those with and without pruritus but that $\mathrm{k}$-opioid expression is significantly lower in dialysis patients with pruritus than in those without pruritus. Another report found a significant negative correlation between the severity of pruritus and $\mathrm{k}$-opioid receptor expression [45]. Based on these past studies, nalfurafine hydrochloride is expected to activate the $\mathrm{k}$-opioid system not only in the central nervous system but also in the peripheral skin, thereby suppressing pruritus.

After the introduction of our treatment algorithm, the percentage of patients who used nalfurafine hydrochloride remained almost unchanged from 2013 to 2016-at $23.7 \%, 22.6 \%, 22.1 \%$, and $21.5 \%$ in $2013,2014,2015$, and 2016, respectively. However, there was a significant decrease to $13.5 \%$ and $14.3 \%$ in 2017 and 2018 , respectively. The reason for this could be that we have been actively expanding OHDF since 2015, which is able to remove uremic substances that cause pruritus, and thus there were fewer patients in whom nalfurafine hydrochloride was indicated. However, although the frequency of using nalfurafine hydrochloride has declined, it remains an important option in the treatment algorithm.

Furthermore, identifying the best dialysis condition for each patient by reviewing the hemodialysis method, medication, and test data in accordance with the treatment algorithm appeared to be effective for alleviating pruritis. The dialysis dose index spKt/Vurea in 20162018 was significantly higher than that in 2009 (Table 2). In addition, OHDF, the use of which was expanded in 2015, is effective at removing suspected causes of pruritis, including low molecular weight proteins such as $\beta 2$-microglobulin [46] and protein-bound uremic toxins such as indoxyl sulfate and p-cresyl sulfate [47]; therefore, it should be beneficial for patients with pruritis caused by those substances. We aim to achieve a $\geq 80 \%$ removal for $\beta 2$-microglobulin and a $30-40 \%$ ( $\geq 40 \%$ in refractory cases) removal for $\alpha 1$-microglobulin in OHDF [30]. These may have contributed to the marked improvement in pruritus severity (e.g., the VAS score) and insomnia due to pruritus since 2015 as well as the reduced frequency of pruritus since 2016.

Meta-analyses conducted overseas have reported that gabapentin $[9,48,49]$ and montelukast $[9,50]$ are effective for treatment of HAP. Gabapentin prevents secretion of neurotransmitters such as glutamate, substance $P$, and calcitonin gene-related peptides at the hyperexcitable state by acting on $\alpha 2 \delta$ subunits of voltage-gated calcium channels in the central and peripheral nervous systems, thereby increasing the threshold for the perception of itchiness. Its side effects include drowsiness and dizziness, and thus patients are advised not to drive or operate dangerous machinery when taking it. Other side effects include weight gain and ocular disease, which should be treated appropriately should they occur. Also, gabapentin is not indicated for treatment of HAP in Japan and is not covered by the national health insurance system. Therefore, treatment with gabapentin must be sufficiently explained to patients and it must be carefully administered, starting with a low dose to avoid side effects. For these reasons, we did not include gabapentin in our treatment algorithm. Montelukast was shown to 
suppress the expression of inflammatory mediators such as substance $P$ and is a neurotransmitter involved in the sensation of itch, but it too is not indicated for treatment of HAP in Japan, and thus we did not include it in our treatment algorithm. However, once these medications are approved for the treatment of HAP, we will review and update the treatment algorithm as necessary.

There are several limitations to this study. First, this is a retrospective study, and due to the absence of a control group, it is difficult to prove that the treatment algorithm was the most important factor in improving HAP. Furthermore, since multiple factors are involved in a complex manner in the cause of HAP, it was difficult to verify the roles played by dialysis method, selection of medications, and skincare.

\section{Conclusions}

This study revealed the usefulness of our treatment algorithm for HAP and also identified future challenges, such as the need to further promote switching to less potent topical steroids and discontinuation of topical steroids. Further prospective studies are required to confirm the role of each treatment intervention in a comprehensive cause-specific approach to the treatment of HAP.

\section{Abbreviations}

DOPPS: Dialysis Outcomes and Practice Patterns Study; HAP: Hemodialysisassociated pruritus; OHDF: Online hemodiafiltration; VAS: Visual analogue scale

\section{Acknowledgements}

The authors are grateful to all the medical staff who participated in this study.

\section{Authors' contributions}

NT established the new treatment algorithm for hemodialysis-associated pruritus and conceived the study and wrote the first draft of this manuscript. TY contributed to the study design, coordinated the study, and conducted the statistical analysis. JK, HK, ST, MM, and TM contributed to the study design and were involved in the production of the first draft of parts of this manuscript. The authors read and approved the final manuscript.

\section{Funding}

This research received no specific grant from any funding agency in the public, commercial, or not-for-profit sectors.

\section{Availability of data and materials}

The datasets used and/or analyzed during the current study are available from the corresponding author on reasonable request.

\section{Declarations}

\section{Ethics approval and consent to participate}

This study was conducted with the approval of the Institutional Review Board of Tsuchiya General Hospital (no. E191216-1). Prior verbal consent was obtained from all patients enrolled in this study. The fact that patients provided consent was recorded in their medical records.

\section{Consent for publication}

Not applicable.

\section{Competing interests}

The authors declare that they have no competing interests.

\section{Author details}

${ }^{1}$ Akane-Foundation Omachi Tsuchiya Clinic, 2-8-35 Omachi Higashi, Asa Minami-ku, Hiroshima 731-0124, Japan. ${ }^{2}$ Department of Artificial Organs, Akane-Foundation, Tsuchiya General Hospital, Hiroshima, Japan.

${ }^{3}$ Akane-Foundation Nakajima Tsuchiya Clinic, Hiroshima, Japan. ${ }^{4}$ Department of Nephrology, Hiroshima University Hospital, Hiroshima, Japan.

Received: 13 January 2021 Accepted: 22 April 2021

Published online: 26 May 2021

\section{References}

1. Pisoni RL, Wikström B, Elder SJ, Akizawa T, Asano Y, Keen ML, et al. Pruritus in haemodialysis patients: international results from the Dialysis Outcomes and Practice Patterns Study (DOPPS). Nephrol Transplant. 2006;21:3495-505.

2. Narita I, Alchi B, Omori K, Sato F, Ajiro J, Saga D, et al. Etiology and prognostic significance of severe uremic pruritus in chronic hemodialysis patients. Kidney Int. 2006;69:1626-32.

3. Kimata N, Fuller DS, Saito A, Akizawa T, Fukuhara S, Pisoni RL, et al. Pruritus in hemodialysis patients: results from the Japanese Dialysis Outcomes and Practice Patterns Study (JDOPPS). Hemodial Int. 2014;18:657-67.

4. Remakrishnan K, Bond TC, Claxton A, Sood VC, Kootsikas M, Agnese W, et al. Clinical characteristics and outcomes of end-stage renal disease patients with self-reported pruritus symptoms. Int J Nephrol Renovasc Dis. 2014;7:1-12.

5. Mathur VS, Lindberg J, Germain M, Block G, Tumlin J, Smith M, et al. ITCH National Registry Investigators: a longitudinal study of uremic pruritus in hemodialysis patients. Clin J Am Soc Nephrol. 2010;5:1410-9.

6. Shirazian S, Aina O, Park Y, Chowdhury N, Leger K, Hou L, et al. Chronic kidney disease-associated pruritus: impact on quality of life and current management challenges. Int J Nephrol Renovasc Dis. 2017;10:11-26.

7. Grochulska K, Ofenloch RF, Mettang T, Weisshaar E. Mortality of haemodialysis patients with and without chronic itch: a follow-up study of the German Epidemiological Hemodialysis Itch Study (GEHIS). Acta Derm Venereol. 2019;99:423-8.

8. Rayner HC, Larkina M, Wang M, Graham-Brown M, van der Veer SN, Ecder T, et al. International comparisons of prevalence, awareness, and treatment of pruritus in people on hemodialysis. Clin J Am Soc Nephrol. 2017;12:2000-7.

9. Simonsen E, Komenda P, Lerner B, Askin N, Bohm C, Shaw J, et al. Treatment of uremic pruritus: a systematic review. Am J Kidney Dis. 2017; 70(5):638-55.

10. Suzuki $\mathrm{H}$, Omata $\mathrm{H}$, Kumagai $\mathrm{H}$. Recent advances in treatment for uremic pruritus. Open J Nephrol. 2015;5:1-13.

11. Mettang T, Kremer AE. Uremic pruritus. Kidney Int. 2015;87:685-91.

12. Takahashi N, Yoshizawa T, Kumagai J, Kawanishi H, Moriishi M, Masaki T, et al. Response of patients with hemodialysis-associated pruritus to new treatment protocol with nalfurafine hydrochloride: a retrospective surveybased study. Ren Replace Ther. 2016;2:27.

13. Japan Meteorological Agency. Historical weather data search [in Japanese] https://www.data.jma.go.jp/obd/stats/etrn/index.php?prec_no=67\&block_ no $=47765 \&$ year $=2013 \&$ month $=5 \&$ day $=4 \&$ view. Accessed on February 22, 2021.

14. Bolanos CG, Pham NM, Mair RD, Meyer TW, Sirich TL. Metabolomic analysis of uremic pruritus in patients on hemodialysis. PLoS One. 2021;16(2): e0246765.

15. Yamada $\mathrm{S}$, Sakurai $\mathrm{H}$, Kasuga $\mathrm{H}$, Kawahara $\mathrm{H}$. Investigation of the status of uremic pruritus in hemodialysis patients and the efficacy of nalfurafine hydrochloride -questionnaire administered to 1,936 patients from 17 clinics in Tokai area of Japan. J Jpn Soc Dial Ther. 2012; 45(12): 1133-1140 (In Japanese).

16. Oeda S, Takahashi H, Yoshida H, Ogawa Y, Imajo K, Yoneda M, et al. Prevalence of pruritus in patients with chronic liver disease: a multicenter study. Hepatol Res. 2018;48(3):E252-62.

17. Furue M, Ebata T, Ikoma A, Takeuchi S, Kataoka Y, Takamori K, et al. Verbalizing extremes of the visual analogue scale for pruritus: a consensus statement. Acta Derm Venereol. 2013;93:214-21.

18. Williamson A, Hoggart B. Pain: a review of three commonly used pain rating scales. J Clin Nurs. 2005;14:798-804. 
19. Reich A, Heisig M, Phan NQ, Taneda K, Takamori K, Takeuchi S, et al. Visual analogue scale: evaluation of the instrument for the assessment of pruritus. Acta Derm Venereol. 2012;92:497-501.

20. Phan NQ, Blome C, Fritz F, Gerss J, Reich A, Ebata T, et al. Assessment of pruritus intensity: prospective study on validity and reliability of the visual analogue scale, numerical rating scale and verbal rating scale in 471 patients with chronic pruritus. Acta Derm Venereol. 2012;92:502-7.

21. Shiratori A. Therapeutic outcomes of the use of mequitazine (LM-209) in severe dermatological diseases. Nishinihon J Dermatol. 1983; 45: 470-473. (in Japanese)

22. Masakane I. High-quality dialysis: a lesson from the Japanese experience. Nephrol Dial Transplant Plus. 2010;3(Suppl 1):i28-35.

23. Kato A, Takita T, Furuhashi M, Takahashi T, Watanabe T, Maruyama Y, et al. Polymethylmethacrylate efficacy in reduction of renal itching in hemodialysis patients: crossover study and role of tumor necrosis factor-a. Artif Organs. 2001;25:441-7.

24. Lin HH, Liu YL, Liu JH, Chou CY, Yang YF, Kuo HL, et al. Uremic pruritus, cytokines, and polymethylmethacrylate artificial kidney. Artif Organs. 2008; 32:468-72.

25. Aoike I. Clinical significance of protein adsorbable membranes-long-term clinical effects and analysis using a proteomic technique. Nephrol Dial Transplant. 2007;22:13-9.

26. Aucella F, Vigilante M, Gesuete A. Review: the effect of polymethylmethacrylate dialysis membranes on uraemic pruritus. Nephrol Dial Transplant Plus. 2010;3(Suppl 1):i8-11.

27. Uchiumi N, Sakuma K, Sato S, Matsumoto Y, Kobayashi H, Toriyabe K, et al. The clinical evaluation of novel polymethyl methacrylate membrane with a modified membrane surface: a multicenter pilot study. Ren Replace Ther. 2018;4:32.

28. Jiang X, Ji F, Chen ZW, Huang QL. Comparison of high-flux hemodialysis with hemodialysis filtration in treatment of uraemic pruritus: a randomized controlled trial. Int Urol Nephrol. 2016;48(9):1533-41.

29. Masakane I. How to prescribe hemodialysis or hemodiafiltraion in order to ameliorate dialysis-related symptoms and complications. Contrib Nephrol. 2011;168:53-63.

30. Sakurai K. Biomarkers for evaluation of clinical outcomes of hemodiafiltration. Blood Purif. 2013;35(Suppl 1):64-8.

31. Karkar A, Abdelrahman M, Locatelli F. A randomized trial on health-related patient satisfaction level with high-efficiency online hemodiafiltration versus high-flux dialysis. Blood Purif. 2015;40:84-91.

32. Takahashi N, Yoshizawa T, Tsuchiya S. Current status and treatment strategies of hemodialysis-associated pruritus. Contrib Nephrol. 2018;196: 88-95.

33. Hattori A, Taguchi N, Ohtomo S, Kaburagi Y. General skin lesions in hemodialysis patients. Kitakanto Med J. 1987;37:539-547. (in Japanese)

34. Szepietowski JC, Reich A, Schwartz RA. Uremic xerosis. Nephrol Dial Transplant. 2004;19:2709-12.

35. Tominaga M, Ozawa S, Tengara S, Ogawa H, Takamori K. Intraepidermal nerve fibers increase in dry skin of acetone-treated mice. J Dermatol Sci. 2007:48:103-11.

36. Han L, Dong X. Itch mechanisms and circuits. Annu Rev Biophys. 2014;43: 331-55.

37. Kiliç Akça N, Taşçi S. An important problem among hemodialysis patients: uremic pruritus and affecting factors. Turk J Nephrol. 2014;23 210-6.

38. Kamo A, Tominaga M, Negi O, Tengara S, Ogawa H, Takamori K. Topical application of emollients prevents dry skin-inducible intraepidermal nerve growth in acetone-treated mice. J Dermatol Sci. 2011;62:63-6.

39. Katoh N, Ooya Y, Ikeda M, Ebihara T, Katayama I, Saeki H, et. al.. Clinical practice guidelines for atopic dermatitis. Jpn J Dermatol. 2018;128(12):24312502. (in Japaenese)

40. Kumagai H, Saruta T, Matsukawa S, Utsumi J. Prospects for a novel K-opioid receptor agonist, TRK-820, in uremic pruritus. Itch: basic mechanisms and therapy. New York: Marcel Dekker; 2004. p. 279-86.

41. Nagase H, Hayakawa J, Kawamura K, Kawai K, Takezawa Y, Matsuura H, et al. Discovery of a structurally novel opioid kappa-agonist derived from 4,5epoxymorphinan. Chem Pharm Bull (Tokyo). 1998;46:366-9.

42. Kumagai H, Ebata T, Takamori K, Muramatsu T, Nakamoto H, Suzuki H. Effect of a novel kappa-receptor agonist, nalfurafine hydrochloride, on severe itch in 337 haemodialysis patients: a phase III, randomized, double-blind, placebo-controlled study. Nephrol Dial Transplant. 2010;25:1251-7.
43. Bigliardi PL, Bigliardi-Qi M, Buechner S, Rufli T. Expression of mu-opiate receptor in human epidermis and keratinocytes. J Invest Dermatol. 1998; 111:297-301.

44. Bigliardi PL, Stammer H, Jost G, Rufli T, Büchner S, Bigliardi-Qi M. Treatment of pruritus with topically applied opiate receptor antagonist. J Am Acad Dermatol. 2007:56:979-88.

45. Wieczorek A, Krajewski P, Kozioł-Gałczyńska M, Szepietowski JC. Opioid receptors expression in the skin of hemodialysis patients suffering from uremic pruritus. J Eur Acad Dermatol Venereol. 2020. https://doi.org/1 $0.1111 / j d v .16360$.

46. Andoh T, Maki T, Li S, Uta D. B2-microglobulin elicits itch-related responses in mice through the direct activation of primary afferent neurons expressing transient receptor potential vanilloid 1. Eur J Pharmacol. 2017:810:134-40.

47. Wang CP, Lu YC, Tsai IT, Tang WH, Hsu CC, Hung WC, et al. Increased levels of total $p$-cresylsulfate are associated with pruritus in patients with chronic kidney disease. Dermatology. 2016;232:363-70.

48. Eusebio-Alpapara KMV, Castillo RL, Dofitas BL. Gabapentin for uremic pruritus: a systematic review of randomized controlled trials. Int J Dermatol. 2020;59(4):412-22.

49. Feng $W-W$, Yuan B, Shen F-Y, Fan W-Y, Mei D-S, Bao B-Y, et al. Efficacy of uremic pruritus treatment in patients undergoing hemodialysis, a network meta-analysis for randomized clinical trials. Nephrol Ther. 2021; 17(1):30-4.

50. Gao C-Q, Zhou J-J, Tan Y-Y, Tong C-J. Effectiveness of montelukast for uremic pruritus in hemodialysis patients: a protocol for systematic review and meta-analysis. Medicine. 2020;99(46):e23229.

\section{Publisher's Note}

Springer Nature remains neutral with regard to jurisdictional claims in published maps and institutional affiliations.
Ready to submit your research? Choose BMC and benefit from:

- fast, convenient online submission

- thorough peer review by experienced researchers in your field

- rapid publication on acceptance

- support for research data, including large and complex data types

- gold Open Access which fosters wider collaboration and increased citations

- maximum visibility for your research: over $100 \mathrm{M}$ website views per year

At $\mathrm{BMC}$, research is always in progress.

Learn more biomedcentral.com/submissions 